4th International Scientific Conference SEC-IASR 2019, Galati, Romania, 7th - 8th June, 2019

\title{
The Importance of the Proprioceptive Training and its Results in the Junior Category Sports Training
}

\author{
Ştefan ALECU, Dragoş IONESCU - BONDOC, \\ Alexandru IONESCU - BONDOC, Cristian IONESCU - \\ BONDOC, Florentina NECHITA
}

https://doi.org/10.18662/lumproc/sec-iasr2019/01

How to cite: Alecu, S., Ionescu - Bondoc, D., Ionescu - Bondoc, A., Ionescu Bondoc, C., \& Nechita, F. (2020). The Importance of the Proprioceptive Training and its Results in the Junior Category Sports Training. In S. Marin \& P. Moisescu (vol. eds.), Lumen Proceedings: Vol. 12. 4th International Scientific Conference SEC-IASR 2019 (pp. 1-9). Iasi, Romania: LUMEN Publishing House.

https://doi.org/10.18662/lumproc/sec-iasr2019/01 



\title{
The Importance of the Proprioceptive Training and its Results in the Junior Category Sports Training
}

\author{
Ştefan ALECU1 ${ }^{1}$, Dragoş IONESCU - BONDOC ${ }^{2}$, Alexandru \\ IONESCU - BONDOC ${ }^{3}$, Cristian IONESCU - BONDOC ${ }^{4}$, \\ Florentina NECHITA5 ${ }^{*}$
}

Abstract

In this study we aim to demonstrate the fundamental role of proprioceptive training as an integral part of the junior category sports training in the $110 \mathrm{~m}$ hurdles. For this we tested, before and after the training period, using proprioceptive techniques and exercises to influence the technique of the burdle runner at the two subjects chosen for this experiment, and the results obtained revealed the progress achieved by them in within the parameters we considered relevant to the study. The objective of this study is to reveal the importance of proprioceptive training in correcting the technique of burdle running, but also the parameters that change, and their values. The engine program applied between the initial test and the final test is based on a training optimization adjustment system, focusing on the balance of transition and reassessment of the kinetic sensations from the pushing to the landing, taking into account a series of transformations made during the two tests through which the athlete consciously correct the technical mistakes and improve them.

As a result of proprioceptive training, they have considerably improved their perception of the burdle and the parameters we need to measure for the progress. The more we develop the proprioceptive capabilities during the junior category, the more likely it is to correct its burdle runner and acquire a hurdle running technique, closest to the reference model, the world champion in $110 \mathrm{~m}$ burdles.

Keywords: proprioceptive training; 110 m burdles; burdle technique; athletics; training.

\footnotetext{
1 Transilvania University, Brasov, Romania, alecustefan@yahoo.com

2 Transilvania University, Brasov, Romania, dragosbionescu@yahoo.com

3 Transilvania University, Brasov, Romania, dragosbionescu@yahoo.com

${ }_{4}^{4}$ Transilvania University, Brasov, Romania, dragosbionescu@yahoo.com

5 Transilvania University, Brasov, Romania, florentina.nechita@unitbv.ro 


\section{Introduction}

During exercises and motor acts specific to technical executions, kinetic sensations coupled with balance sensations make up the group of proprioceptive sensations, which are a reflection of the excitations produced within the body of the sport and especially in the muscles activated by specific excitators of the proprioceptors, in the motor analyzer.

Proprioceptors are due to the miotatic reflex and they are constituted by the contractions of the muscles, the pressures and tractions exerted on the tendons and joints, manifested in the specific sports movements practiced.

The kinesthetic sense ensures tonic reflexes of posture and the coordinated character of the movements of the athlete [2].

Proprioception is defined in Ellis Cashmore's work as "the sense of movement," with reference to the stimuli produced and perceived within the body, including sensory processes made at the level of vestibular, optical, tactile, visual analyzers[1].

In the conception of author Bondoc Ionescu D., the technical training brings together "the set of measures, means and methods used in learning the technical elements and procedures specific to a sport branch." The same author states: the best way to acquire and the improvement of the technique is the individualization of the training [3].

\section{Problem Statement}

Theimpulse (propulsion) towards the hurdle - the runner acts on the ground by means of a one-sided support (on one leg). During the foot ground interaction, the propulsion forces are applied to the runner and the muscle tension is maximum. The development of muscle strength can be considered as a favorable means for achieving the best efficiency of the movement.

Balancing (development of the muscular support pelvis): The stiffness of the pelvis is determined in terms of efficacy of the support. In fact, the runner must be considered a deformable mechanical system. At the moment of support, the ground reaction forces can cause the relative unity of certain elements of this ensemble, some with respect to others. (Pooltrunk)[4].

The exercises to develop muscle strength of the so-called "muscular support for pelvis basin assembly", will be a constant element of specific work in sprint hurdles. 
The dynamic balance of the moving body and the continuity of action: During the support phase, the center axis of the body performs a rotation motion around the support leg. This rotation movement must be at the same time extremely fast forward and stopped at the end of the support to maintain the overall balance of the body during the flight phase over the hurdle that will follow [5].

The loose segments (first, the free leg, the osculant and, secondly, the arms) provide much of this double function. As part of the muscular force development activity, the muscular strain that provided the forward turn and rotating the free foot of the trailer over the hurdle should be considered.[6]

\section{Research Questions/Aims of the research}

Subjects surveyed participated in the training, according to a program proposed at national competitions.

Between the Initial Testing and the Final Testing, a specific training program based on specific technique of the hurdle runner technique was applied to the $110 \mathrm{~m}$ hurdles and nonspecific sample. The dynamic of the effort was planned in the months of the experiment in an individualized manner on each subject, taking into account the somato-functional characteristics of each individual.

The results of the specific tests and non-specific training on each subject are organized and presented in the following tables with the percentage of effort components as well as the results obtained in the initial and final control samples during the experiment. The engine program applied between the initial test and the final test is based on a training optimization adjustment system, focusing on the balance of transition and reassessment of the kinetic sensations from impulse to landing, taking into account a series of transformations made during the two tests through which the athlete consciously corrects the technical mistakes and implicitly improves them.

Records were made from the side plan to capture as accurately as possible the angles and distances between the hurdle and the frontal passage phases and to capture the angle between the attacking foot and the ground when landing. 
Ştefan ALECU et al. | Lumen Proceedings 12 | SEC-IASR 2019

\section{Research Methods}

For this experiment to be concludent, one of the methods we used was the kinematic recording and analysis and interpretation the data using Dartfish software.

An also used method was the statistical-mathematical method to highlight the differences. We inserted the graphics and the tabels to achieve a better visual representation of the obtained results

\section{Findings}

\subsection{Structure}

We proposed the following proprioceptive exercise program, phased and adapted to the specifics of each subject:

1.step shattered on $50 \mathrm{~m}$ distance.

2. pass over 10 hurdles located 1.5 meters apart.

3. crossing over double hurdles.

4. attacking the hurdle located at the right of a trellis or wall.

5. passing the trailer foot over the hurdle, the subject holding the arms in front of a bar.

6. starting from the bottom and running to the first deck fence in a fixed area marked on the ground.

7. passing the attack foot through a certain area on the hurdle.

The proprioceptive training program took place between $15^{\text {th }}$ of November 2018 and $15^{\text {th }}$ of March 2019.

The individualized proprioceptive program has the role of improving the coordinating capacities of the subjects in order to achieve the final goal: optimizing the technique of the hurdle runner.

After the initial testing, the kinematic records were presented to the subjects, and together with $\mathrm{Mr}$. PhD. and coach Dragoş Ionescu Bondoc, the technical execution errors were studied, interpreted and corrected.

The subjects were advised on the potential for correction of errors and the progress that can be achieved by repeated and continuous analysis of their mistakes in the phases of the hurdle runner, but also by an individualized proprioceptive training program, oriented to an impulse with $\mathrm{a}$ as sharp as possible, a faster, clustered and balanced flight phase, and a safe landing towards a forward projection of the CGM to allow for an optimum run-in between the hurdles. 
Ştefan ALECU et al. | Lumen Proceedings 12 | SEC-IASR 2019

The individualized proprioceptive program has the role of improving the coordinating capacities of the subjects in order to achieve the final goal: optimizing the technique of the hurdle running step [7].

Figure 1.Subject no. 1, initial test
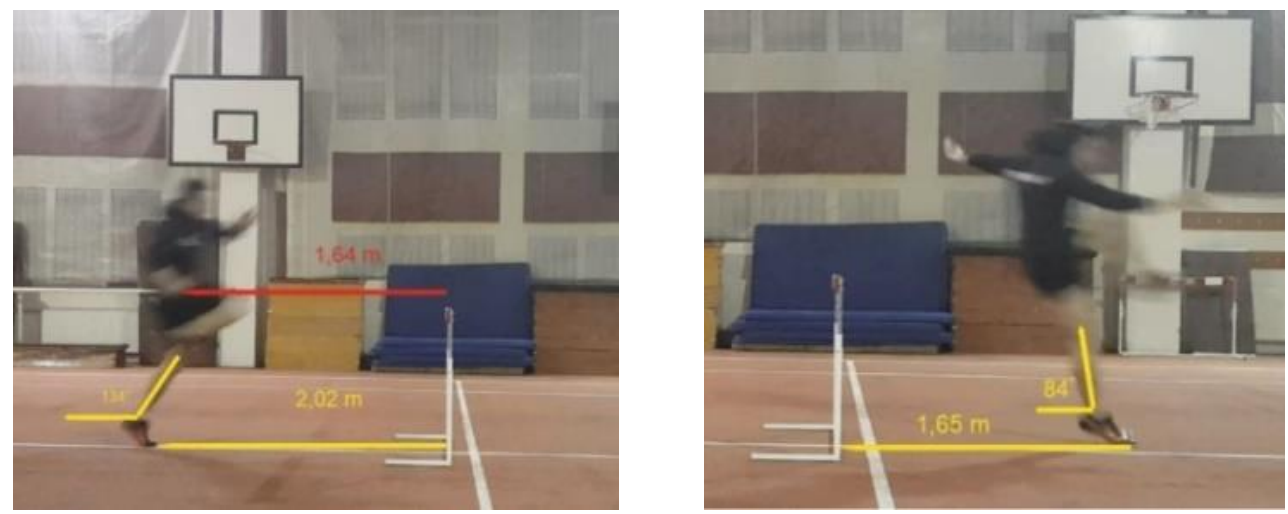

Figure 2.Subject no. 1, final test
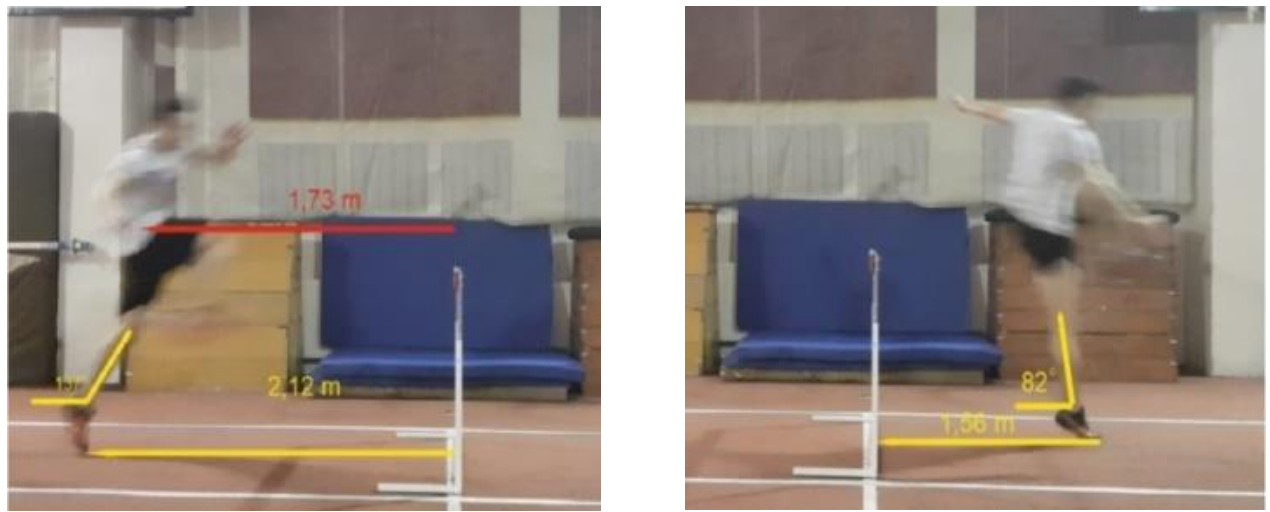
Ştefan ALECU et al. | Lumen Proceedings 12 | SEC-IASR 2019

Figure 3.Subject no. 2, initial test
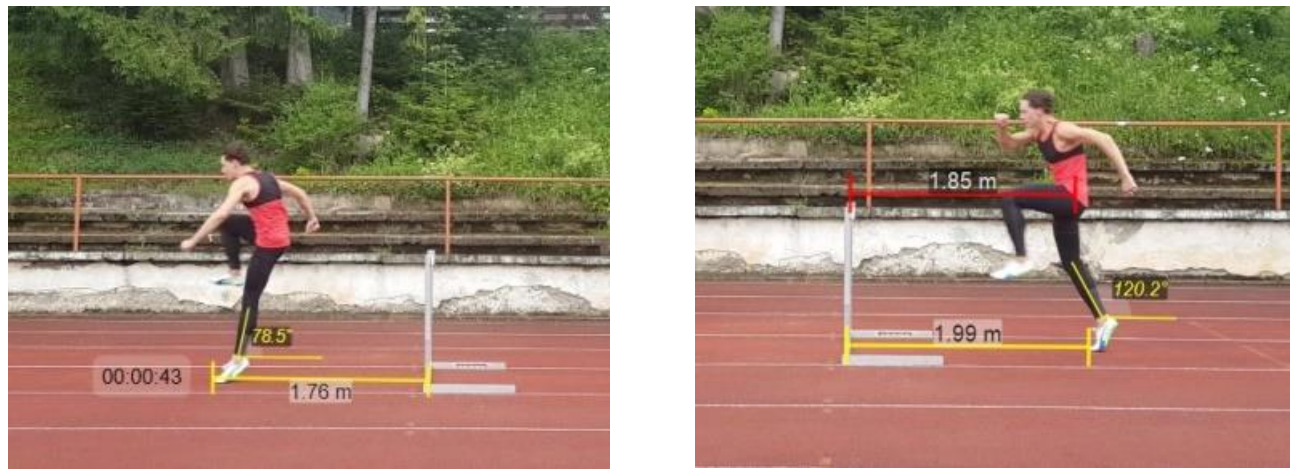

Figure 4.Subject no. 2, final test
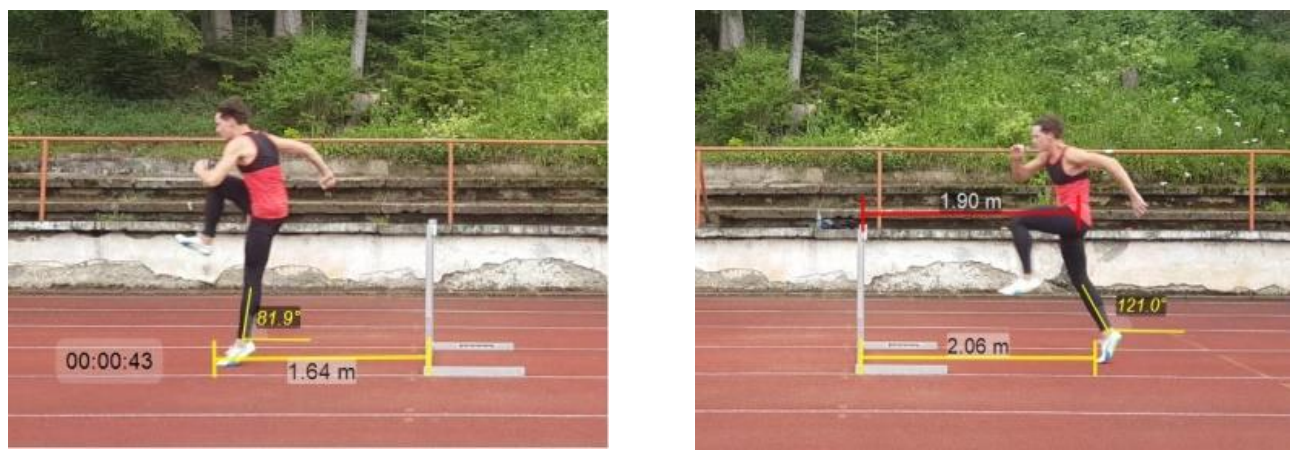

\subsection{Tables}

Table 1.Kinematic parameters registered for subject no. 1 - comparison between initial and final testing

\begin{tabular}{llccc}
\hline No & Kinematic parameters 110 m hurdles & $\begin{array}{c}\text { Initial } \\
\text { test }\end{array}$ & $\begin{array}{c}\text { Final } \\
\text { test }\end{array}$ & Diff. \\
\hline 1 & Maximum CGM lifting above the hurdle & $0.45 \mathrm{~m}$ & $0.38 \mathrm{~m}$ & $-0.07 \mathrm{~m}$ \\
2 & Value of attack angle & $134^{\circ}$ & $137^{\circ}$ & $3^{\circ}$ \\
3 & Value of landing angle & $84^{\circ}$ & $82^{\circ}$ & $-2^{\circ}$ \\
4 & Horizontal distance - attack starts & $2.02 \mathrm{~m}$ & $2.12 \mathrm{~m}$ & $0.1 \mathrm{~m}$ \\
5 & Horizontal distance - landing starts & $1.65 \mathrm{~m}$ & $1.56 \mathrm{~m}$ & $-0.09 \mathrm{~m}$ \\
\hline
\end{tabular}


Ştefan ALECU et al. | Lumen Proceedings 12 | SEC-IASR 2019

Table 2. Kinematic parameters registered for subject no. 2 - comparison between initial and final testing

\begin{tabular}{llccc}
\hline No & Kinematic parameters $110 \mathrm{~m}$ hurdles & $\begin{array}{c}\text { Initial } \\
\text { test }\end{array}$ & $\begin{array}{c}\text { Final } \\
\text { test }\end{array}$ & Diff. \\
\hline 1 & Maximum CGM lifting above the hurdle & $0.45 \mathrm{~m}$ & $0.37 \mathrm{~m}$ & $-0.08 \mathrm{~m}$ \\
2 & Value of attack angle & $120.2^{\circ}$ & $121^{\circ}$ & $0.8^{\circ}$ \\
3 & Value of landing angle & $78.5^{\circ}$ & $81.9^{\circ}$ & $3.4^{\circ}$ \\
4 & Horizontal distance - attack starts & $1.99 \mathrm{~m}$ & $2.06 \mathrm{~m}$ & $0.07 \mathrm{~m}$ \\
5 & Horizontal distance - landing starts & $1.76 \mathrm{~m}$ & $1.64 \mathrm{~m}$ & $-0.12 \mathrm{~m}$ \\
\hline
\end{tabular}

\subsection{Graphics}

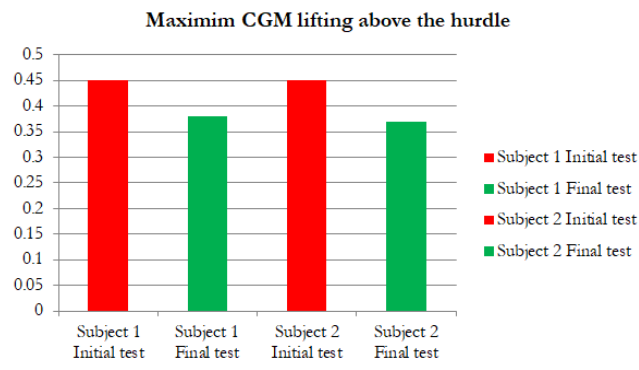

(less is better)

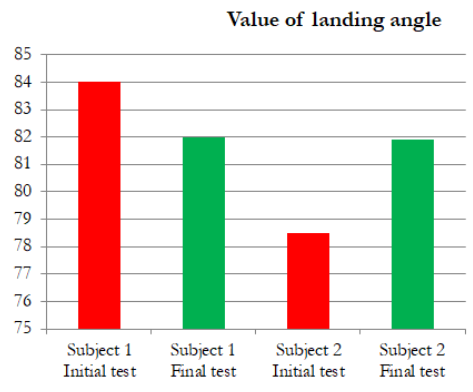

(more is better)

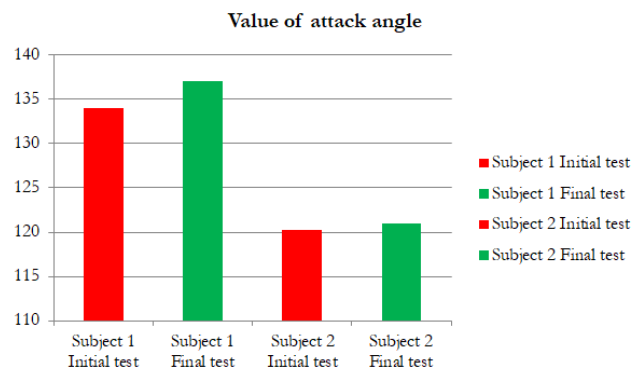

(more is better)

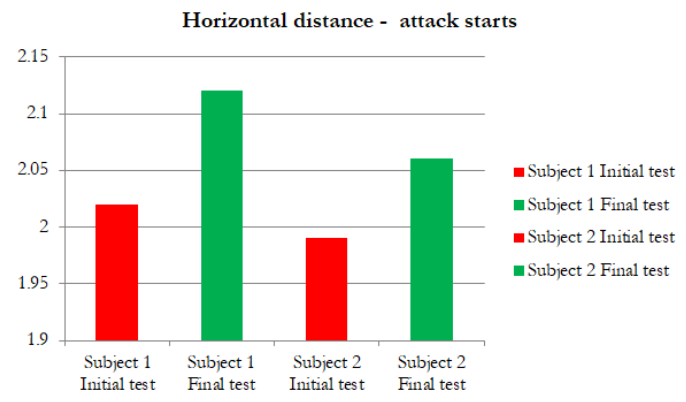

(more is better) 
Ştefan ALECU et al. | Lumen Proceedings 12 | SEC-IASR 2019

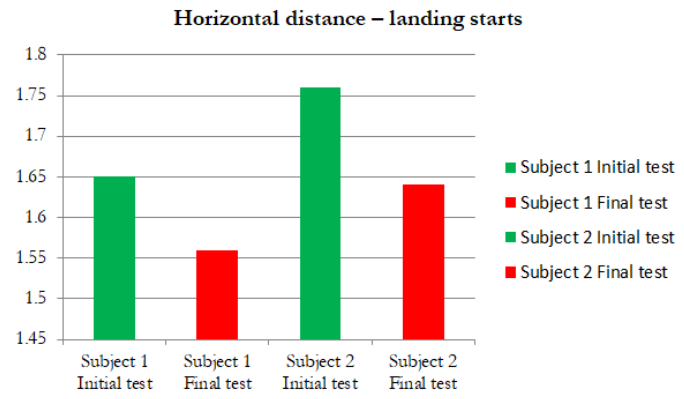

(less is better)

\subsection{Statistic-mathematical interpretation}

Table 3. Kinematic parameters statistic-mathematical interpretation

\begin{tabular}{|c|c|c|c|c|c|c|c|c|c|c|}
\hline \multicolumn{11}{|c|}{ Statistic-mathematical interpretation } \\
\hline \multirow{2}{*}{ Index } & \multicolumn{5}{|c|}{ Initial test } & \multicolumn{5}{|c|}{ Final test } \\
\hline & Vi & $\mathrm{Xi}$ & Dif & $\mathrm{V} \%$ & Vf & $\mathrm{Xf}$ & Dif & $\mathrm{V} \%$ & & \\
\hline $\begin{array}{l}\text { Maximum CGM } \\
\text { lifting above the } \\
\text { hurdle }\end{array}$ & 0.45 & 0.45 & 0.45 & 0 & $0.00 \%$ & 0.38 & 0.37 & 0.375 & 0.01 & $2.67 \%$ \\
\hline $\begin{array}{l}\text { Value of attack } \\
\text { angle }\end{array}$ & 134 & 120.2 & 127.1 & 13.8 & $\begin{array}{c}10.86 \\
\%\end{array}$ & 137 & 121 & 129 & 16 & $\begin{array}{c}12.40 \\
\%\end{array}$ \\
\hline $\begin{array}{l}\text { Value of landing } \\
\text { angle }\end{array}$ & 84 & 78.5 & 81.25 & 5.5 & $6.77 \%$ & 82 & 81.9 & 81.95 & 0.1 & $0.12 \%$ \\
\hline $\begin{array}{l}\text { Horizontal } \\
\text { distance - attack } \\
\text { starts }\end{array}$ & 2.02 & 1.99 & 2.005 & 0.03 & $1.50 \%$ & 2.12 & 2.06 & 2.09 & 0.06 & $2.87 \%$ \\
\hline $\begin{array}{l}\text { Horizontal } \\
\text { distance - landing } \\
\text { starts }\end{array}$ & 1.65 & 1.76 & 1.705 & -0.11 & $\begin{array}{c}- \\
6.45 \%\end{array}$ & 1.56 & 1.64 & 1.6 & -0.08 & $5.00 \%$ \\
\hline
\end{tabular}

\section{Discussions}

After the individualized training period, the two subjects were subjected to the final test, where the improvement of all the parameters studied was found, especially in the case of subject 2, a better prepared and experienced athlete.

Based on the evaluation of the research results, it was found that the proprioceptive training program worked almost entirely, regressing only in the case of the value of the landing angle for the subject 2 due to a technical error from the moment of testing.

\section{Each author has equally contributed to experimental research}




\section{Conclusions}

1. The conclusion we draw from the tests of the two subjects is that, as a result of proprioceptive programs and dosing of effort from training plans, they have considerably improved their perception of the hurdle and the parameters of the hurdle runner.

2. Both subjects needed automation of the detachment site and the onset of the hurdle attack, and after the proprioceptive training program, they were able to acquire an automation of this phase of the hurdle running step.

3. We recommend the increase of the coordination capacities with proprioceptive exercises focused on the phases of the technical structure to be executed in order to achieve better results in competitions

\section{References}

[1] Cashmore E. Sport and Exercise Psychology. The Key Concepts; 2008. pp. 346-347

[2] Epuran M. Motricitate şi psihism în activităţile corporale. Prolegomene la o metateoriea activităţilor corporale [Motility and psychism in bodily activities. Prolegomens to a metatheory of bodily activities]. Vol. 2. Bucureşti: Ed. Fest; 2013. p. 512.

[3] Ionescu-Bondoc D. Bazele antrenamentului sportiv. Note de curs intern [Basics of sports training. Internal course notes]. Brasov: Transilvania University of Brasov; 2008. pp.73-74.

[4] Ionescu-Bondoc D. Pregătirea specializată în atletism [Specialized training in athletics]. Braşov: Transilvania University of Brasov; 2007.

[5] Ionescu-Bondoc A, Ionescu-Bondoc C. Bulletin of the Transilvania University of Braşov Series IX: Sciences of Human Kinetics. 2019; 12(61) No. 1. Available from: https://doi.org/10.31926/but.shk.2019.12.61.1.

[6] Ionescu-Bondoc D, Ionescu-Bondoc C, Sabău E, Martoma E. Concepte asupra proceselor de refacere si recuperare in sport [Concepts on the recovery and recovery processes in sports]. Brasov: Transilvania University of Brasov; 2018. pp. 118-119.

[7] Ionescu-Bondoc D, Ionescu-Bondoc A, Nechita F. Tehnica si metodica predarii probelor de atletism cu notiuni de regulament comtetitional [The technique and methodology of teaching athletics samples with notions of comtetitional regulation]. Brasov: Transilvania University of Brasov; 2018. pp. $66-68$. 